\title{
Communicating about gut health to the consumer: presenting the BENEO $^{\circledR}$ Programme
}

\author{
P. A. A. Coussement* \\ Sales \& Marketing/Regulatory Affairs, ORAFTI Active Food Ingredients, Aandorenstraat 1, 3300 Tienen, Belgium
}

\begin{abstract}
Providing sufficient scientific data to be able to make 'health related claims' on foods is quite a challenge. But bringing these claims successfully to the consumer is perhaps an even bigger challenge. Especially when the claims are based on the function of the intestinal tract, as this is a subject that not everybody communicates easily about. In our consumer research, we have focused on how the new consumer thinks and talks about gut health. We found out that he is aware of the existence and the importance of gut microflora. He believes that foods can influence his own flora. At the same time, our research has tested the efficiency of several ways to communicate about these aspects. The consumer reacts quite differently on different marketing concepts. He accepts that natural ingredients can help his gut flora and expects to find such active ingredients in common everyday foods and also in diet supplements. Based on this research, we have condensed the 'prebiotic' message about inulin and oligofructose into a number of simple communications. The best of these were selected for further consumer product testing. The results of this effort form the basis of the BENEO ${ }^{\circledR}$ Programme: a communication platform created by ORAFTI that allows the food industry, in partnership with ORAFTI, to bring a uniform and clear message to the consumer about the health benefits of inulin and oligofructose.
\end{abstract}

\section{Health claims: Scientific substantiation: Gut well-being}

\section{Introduction}

Inulin is extracted from chicory roots, it can be enzymatically hydrolysed to produce oligofructose and eventually fructose. Both inulin and oligofructose are available in a range of industrial products. They are used by the food industry for many reasons, based on both technological and nutritional benefits and advantages.

Among the nutritional benefits, their effect on intestinal function(s) is the main reason why inulin and oligofructose have gained a prime position in the development of functional food. They are non-digestible oligosaccharides that are classified as dietary fibre and stimulate the growth of bifidobacteria flora in the human colon (Roberfroid et al. 1998). This has lead researchers to introduce the concepts of pre- and synbiotics (Gibson \& Roberfroid, 1995). Other interesting physiological effects have since been discovered which are reviewed in this supplement of the British Journal of Nutrition. Some of these properties are already supported by human intervention studies allowing the justification of 'enhanced function claims' (Diplock et al. 1999).

But, regarding the development and marketing of functional foods, truthful, clear and educative communication to the consumers remain a challenge (Roberfroid, 2000). It is the reason why developing new concepts and a new approach to marketing functional foods is needed. These should be based on specific consumer research, especially for inulin and oligofructose, around the subject of 'gastro-intestinal health'. This research should aim at finding out how consumers think and talk about gut health specifically, and how they feel about functional foods in general.

In combining nutritional research, marketing experience and consumer research, ORAFTI has developed the BENEO $^{\circledR}$ communication platform. It is a coordinated and balanced way to communicate about gut health to the consumer.

\section{The BENEO $^{\circledR}$ Programme}

The BENEO $^{\circledR}$ Programme is composed of four main elements:

1. clear, simple and positive messages

2. communication based on science

3. consistent communication from different partners

4. the BENEO $^{\circledR}$ symbol to appear on all products and

Note: For the definition of the terms inulin and oligofructose please refer to the introductory paper (p. S139) and its footnote.

* Corresponding author: Dr P. A. A. Coussement, tel +32 16801 301, email paul.coussement@orafti.com 
carriers of information that participate in the BENEO ${ }^{\circledR}$ Programme.

These four elements are combined to support health messages for everyday foodstuffs for the whole family. The BENEO $^{\circledR}$ symbol stands for the presence of the active ingredients in sufficient amounts to have the effects that are claimed on the product pack, and refers to the BENEO $^{\circledR}$ communication that is available to the consumer.

\section{Clear, simple and positive}

The consumer does not understand the meaning or importance of scientific terms like probiotic, Lactobacillus, oligofructose, inulin, etc., and it is unlikely that the consumer will ever develop an understanding of such terminology when used in foods.

As stated in the ILSI Europe consensus document on concepts for functional foods: 'Consumers must be made aware of the scientific benefits of functional foods and this requires clear and informative communications through messages (claims) on products and in accompanying materials' (Diplock et al. 1999).

Thus, there is a great need for clear information, in a language that consumers understand.

Functional food claims should be simple. Simplicity is one of the essential criteria for successful marketing concepts, but is still of huge importance in marketing functional foods. Keeping the message simple, as opposed to scientific or sophisticated, means: the message should be easy to understand, clear and direct.

Functional Food claims should also be positive for the following reasons: first, most of the existing food regulations do not permit communication about disease prevention by foods, but they do allow 'enhanced function' or 'structure-function' claims (Diplock et al. 1999); second, the consumer is much more interested in positive aspects than the disease prevention functions of the food and consequently disease prevention products will probably be niche products. Functional Foods with a 'positive' message have the potential to become real 'family' products that everybody can consume at any point in time (Coussement, 2000). This aspect is probably the most underestimated aspect of functional food marketing today. Too often, functional foods are believed to be medicines in a food disguise. While the real challenge of functional food marketing is to make healthy people buy the product because of its positive functions for the whole family.

How do the general principles of marketing communication apply when the subject is gut function? In order to learn more about this, ORAFTI have set up a consumer research programme aimed at finding out how to talk about Gut Health. Research was done initially in Belgium, which is often considered as a 'test-market' for foods in Europe. Since then, the research has also been performed in other countries.

\section{Qualitative consumer research}

The first part of the research was qualitative, using a 'focus group' approach. The research in Belgium, as an example, comprised eight groups of consumers. Each group was composed on average of eight persons, in six groups they were comprised entirely of women, in two groups only men. During a 2-h discussion, the consumers were confronted with marketing concepts and communication approaches. The discussions were recorded and evaluated by a panel of marketing experts with experience in this field. This approach has provided information on how consumers think about food, health, intestinal health and especially the language they use to talk about these subjects. This kind of research is extremely interesting to marketing experts and product developers, however, it cannot be compared to 'scientific' research. The results of this research are proposals and guidelines for communication choices, nothing that can be expressed in figures or statistical comparisons.

Some of the most important conclusions of this research were that for the consumers:

- 'Intestinal health' is not a concept used spontaneously. Consumers talk about intestinal well-being or transit.

- An important proportion of people seem in their life confronted with more or less severe problems concerning their intestinal transit.

- However, intestinal health is not an easy subject to talk about. There is a barrier to overcome. This barrier is not very high.

- It is logical and understandable that a product can have a beneficial effect on the bacteria in the gut and therefore have benefits in the long term as well as in the short term.

- An ingredient that improves the gut flora is seen as a natural way of protecting the body and making it function in a better way.

- Consuming functional foods is providing the opportunity to do something for beneficial health in a simple way.

- The term gut flora does exist in the mind of the consumer.

- Gut flora is not a taboo subject.

The examination of different concepts demonstrated that some approaches work, while others don't. It was surprising to see how critical the consumer has become of unknown scientists or professors, whose opinions can be easily contradicted by other so-called experts. Our research confirmed that consumers have high trust in their own 'doctor' or dietician, and on a second level in independent journalists and media.

This research has now been repeated in other countries. Conclusions are comparable in general terms, but they differ in details. The results of this research helped to define precisely how the health benefits of BENEO $^{\circledR}$ should be communicated to the consumer

\section{Quantitative consumer research}

In a second phase of consumer research, actual food products based on the BENEO $^{\circledR}$ concept and containing inulin or oligofructose were tested and evaluated. Although the real purpose of this research was to test the acceptance of the products, several other useful elements came out of this research. The results are mentioned here to illustrate 
how the essential elements of the BENEO $^{\circledR}$ Programme were constructed.

Three groups of 500 women each received a different food product. The products were packaged in white boxes. The positioning concepts of the products were explained to the consumers in an interview before the test phase. The products were tested during 30 days, after which a second interview was planned to collect reactions, experiences and opinions.

The main elements of the product positioning were: the test products were new and contained a 'new active plant fibre that nourishes our own good gut flora'. The food products were powders, packed in individual portions, to be added to the diet.

The most important general conclusions of this research were:

- The concept was attractive, and received a high interest: about $70 \%$ of the consumers classified the products as 'quite' or 'very interesting'.

- The concept was often translated by the consumer as 'to facilitate the transit' or 'good for the gut flora'.

- Many consumers (about 60\%) reported to have experienced advantages: about one third of them had experienced a better transit and about a quarter of the consumers reported a feeling of well-being.

\section{Defining the BENEO ${ }^{\circledR}$ communication elements}

Combining both parts of consumer research, it was concluded that (in the tested market) 'gut health' and 'intestinal well-being' are meaningful for consumers. 'Gut flora' and 'intestinal transit' have become familiar concepts in the mind of the consumer. The fact that it is difficult to talk about it does not mean that a good marketing concept cannot be built on it. Gut health concepts can be simple, positive and scientific. Moreover, it is clear that consumers can actually experience a feeling of increased intestinal well-being when inulin or oligofructose are used.

To the four essential questions that consumers had, a clear answer was defined using the exact words that the consumer understands and likes. The original communications were made in Dutch and French, but could be translated as:

- BENEO $^{\circledR}$, what is it? An active plant fibre.

- Where does it come from? Chicory roots.

- What does it do? It nourishes our own good gut flora.

- What is it good for? For protection of the balance of the intestinal tract, for a better transit and a better calcium absorption.

Consumer research can also guide to select the channels to communicate the BENEO ${ }^{\circledR}$ message to consumers. It is clearly not a matter of massive advertising. The types of media used to communicate are also important, and again, this differs from country to country. In Belgium, there is high emphasis on providing correct information to health professionals, dieticians, nutritionists and physicians.

To help the consumer, there is a free telephone line where questions regarding $\mathrm{BENEO}^{\circledR}$ can be answered. The BENEO ${ }^{\circledR}$ web-site also provides basic and scientific information, and there are several support documents and brochures on different scientific levels available.

\section{BENEO $^{\circledR}$ Scientific Committee}

The BENEO ${ }^{\circledR}$ Scientific Committee is composed of independent scientific experts in health and nutrition. It has several tasks. The first one is putting forward the general principles that all partners in the $\mathrm{BENEO}^{\circledR}$ programme should respect. These principles are general and specific. The general principles are in line with the principles put forward in the ILSI Europe Consensus on Concepts for Functional Foods with a special emphasis on research in humans as the sole basis to support health claims on foods (Diplock et al. 1999). The specific principles are about the types of claims for inulin and oligofructose that are scientifically substantiated. It is clear that these criteria will evolve as more research data become available.

At the moment, the conclusions of the BENEO ${ }^{\circledR}$ Scientific Committee confirm that inulin and oligofructose can be used in food to support claims about the following nutritional effects:

- Inulin and oligofructose are natural carbohydrates that - resist digestion;

- are highly fermented in the colon;

- have a regulating effect on stool frequency and stool production.

- They are dietary fibres with exceptional other properties. They are bifidogenic and prebiotic. They 'feed the good gut bacteria'.

- Inulin and oligofructose increase calcium absorption. This effect might be dose and age dependent.

The second task of the BENEO ${ }^{\circledR}$ Scientific Committee is to monitor the scientific developments in inulin and oligofructose, and to guide the industry's research. As such, the Committee is a source of valuable scientific input. It is not the task of the BENEO ${ }^{\circledR}$ Scientific Committee to approve claims made on foods, but to put forward the principles that all partners should respect.

\section{References}

Coussement P (2000) Back to basics. New Nutrition Business 6, $17-18$.

Diplock AT, Aggett PJ, Ashwell M, Bornet F, Fern EB \& Roberfroid MB (1999) European Consensus on Concepts for Functional Foods. British Journal of Nutrition 81, S1-S27.

Gibson GR \& Roberfroid MB (1995) Dietary modulation of the human colonic microbiota: introducing the concept of prebiotics. Journal of Nutrition 125, 1401-1412.

Roberfroid M (2000) Defining functional foods. In Functional foods, from concept to product, [C Williams and G Gibson, editors]. Cambridge, UK: Woodhead Publishers.

Roberfroid MB, Van Loo JAE \& Gibson R (1998) The bifidogenic nature of chicory inulin and its hydrolysis products. Journal of Nutrition 128, 11-19. 